\title{
Prevalencia de los genotipos del virus del papiloma humano en neoplasia intraepitelial cervical y cáncer cervical en Bogotá
}

\author{
Urdaneta Hernán T.*; Calderón Orlando **; Amórtegui Antonio ***
}

\begin{abstract}
RESUMEN: Se describe la prevalencia del Virus del Papiloma Humano (VPH) mediante Hibridación in Situ (HIS), genotipos 6-11, 1618 y 31-33-35, en una muestra de 266 biopsias cervicales de mujeres residentes en Bogotá, seleccionadas según el criterio de infección por VPH (atipia coilocítica), presencia de Neoplasia Intraepitelial o Cáncer. 27 biopsias (10.1\%) fueron desechadas. La HIS fue positiva en $81 /$ 239 casos (33.9\%). VPH 6-11 se detectó en 6/81 casos (7.4\%), los tipos 16-18 en 47/81 (58.0\%), y los tipos 31-33-35 en 28/81 (34.6\%). 3/12 casos $(\mathbf{2 5 \%})$ de Cáncer Infiltrante fueron positivos a la HIS, todos para 16-18.
\end{abstract}

Teniendo en cuenta la baja prevalencia de 6-11 y la alta de 16-18 y 31-33-35 demostradas en el presente estudio en relación a las informadas en la literatura internacional, se confirma una variación geográfica de la prevalencia de los diferentes tipos de VPM. En esta muestra de Bogotá las displasias, tanto de Bajo como de Alto Grado, tienen una alta prevalencia de los genotipos de VPH de riesgo oncogénico elevado. Este hallazgo es consistente con los estudios epidemiológicos que demuestran que en esta zona geográfica se encuentran los índices más altos del mundo de Carcinoma de Cérvix.

SUMMARY: The prevalence of the Human Papilloma Virus (HPV) was described through hybridization in situ (HIS), genotypes 6-11 18 and 31-33-35, in a sample including 266 cervical biopsies of women living in Bogotá, chosen considering the infection by HPV criteria (collocitic atypia), presence of intra-epithelial neoplasia or cancer. Twenty seven biopsies (10.1\%) were discarded. HIS was positive in 81/ 239 cases $(33,9 \%)$. HVP 6-11 was detected in $6 / 81$ cases $(7,4 \%)$, types $16-18$ in $47 / 81(58 \%)$ and types $31-33-35$ in $28 / 81(34,6 \%)$. $3 / 12$ cases (25\%) of infiltrating cancer were positive to the HIS, all for 16-18.

Taking into account the low prevalence of 6-11 and the high of 16-18 and 31-33-35 demostrated in the present study, related to the ones informed in the international literature, we confirm a geographic variation of the prevalence of the different types of VPM. In this sample of Bogotá the low as well as the high grade dysplasias, have a high prevalence of the genotypes of VPH of high oncogenetic risk. This discovery is consistent with the epidemiological studies that proves that in this geographical zone, the higher rates in the world of cervical carcinoma are found.

\section{Introducción}

Se ha demostrado la asociación de ciertos tipos del Virus del Papiloma Humano (VPH) con un amplio rango de lesiones cervicales, que van desde la Infección Subclínica por VPH (ISP), pasando por Neoplasia Intraepitelial Cervical (NIC) hasta el carcinoma francamente invasivo. A la fecha se han descrito más de 60 genotipos diferentes del virus (23). La infección por un genotipo particular de VPH es específica para un sitio y para un tejido (27), comportándose como un virus epiteliotrófico con predilección por la superficie de la piel y las membranas mucosas incluyendo el epitelio columnar del cérvix uterino (23).

\footnotetext{
* Ginecólogo Obstetra. Profesor Asociado. Hospital Militar Central. Departamento de Ciencias Fisiológicas. Universidad Nacional de Colombia.

** Patólogo. Investigador Científico. Hospital Militar Central.

*** Profesor Titular. Jefe Laboratorio Virología. Hospital Magiee. Universidad de Pittsburgh.
}

\section{Biología de la infección por VPH}

El VPH infecta la piel o las mucosas a través de la penetración de la partícula viral por fisuras microscópicas posiblemente de origen traumático. La infección genital es una enfermedad de transmisión sexual, no se ha informado de transmisión por fómites (34). Al parecer existe transmisión no sexual de los tipos 6 y 11 a la conjuntiva y mucosa nasal, y puede adquirirse a través de transmisión vertical el VPH causante de la papilomatosis laríngea (35).

Inicialmente el virus existe como un plásmide extracromosómico autorreplicante llamado episoma. La replicación del virus en esta fase se presenta sincrónica con la división celular del huésped lo que previene la disminución de las copias virales con el tiempo. En esta fase de incubación, que dura de 6 semanas a 8 meses, extensas áreas del epitelio anogenital son colonizadas sin que se presente ninguna manifestación clínica ni histológica de la infección latente en curso (17).

Entre los individuos expuestos al VPH, el progreso hacia la formación de papiloma es tal vez la excepción 
más que la regla. Se ha informado de la presencia de DNA de VPH en el 10-15\% de los frotis tomados de mujeres "normales" y la gran mayoría de ellas no desarrolla manifestaciones clínicas ni neoplasia (36). Muchos virus del papiloma humano es posible que representen saprofitos y no patógenos (13).

La progresión de una infección latente propia de la replicación episómica viral a una expresión activa propia de la replicación viral productiva o vegetativa requiere la interacción de la permisividad celular, el tipo de virus y el estado inmune del huésped (14). El progreso focal a replicación vegetativa del VPH (con el efecto citopático viral concomitante que conocemos como expresión de la enfermedad parece representar la desaparición local del control celular en un campo de colonización difusa por VPH (16). Los signos morfológicos con que se expresa la infección por VPH varían desde mínimos hasta floridos. En la fase de expresión activa el virus estimula la proliferación de las células parabasales, esto resulta en engrosamiento de la epidermis lo que se designa como acantosis. Con la síntesis de queratina las células escamosas se hacen permisivas para la replicación del virus el cual produce una lesión proliferante (el condiloma acuminado) o una lesión subclínica (llamado por algunos condiloma plano). El efecto citopático del virus se manifiesta por la aparición de unas células ahora conocidas con el nombre de Coilocitos. Estas células se caracterizan por la presencia de un núcleo picnótico, irregular e hipercromático rodeado de un espacio vacío que ocupa gran parte del citoplasma celular. Es frecuente encontrar de dos a cinco núcleos en algunas de las células infectadas (12). La paraqueratosis es otro hallazgo frecuente en las lesiones producidas por el VPH. Esta consiste en la presencia de núcleos picnóticos en las capas más superficiales del epitelio escamoso posiblemente secundaria a queratinización prematura inducida por la infección viral (12).

La expresión tardía eficaz del VPH, que conduce a la formación de viriones, está enlazada a los sucesos celulares de diferenciación y queratinización (37). Debido a que los epitelios genitales tienen una capacidad limitada para la queratinización, el ciclo replicativo viral no siempre continúa hasta el punto de producción deviriones. En su lugar, algunas células muestran un tipo abortivo de interacción célula-virus en la que la actividad genómica temprana del virus no está contrarrestada por la expresión genómica tardía (13). La expresión tardía del genoma viral es necesaria para la formación de la cápsula viral (19). La expresión temprana del genoma viral es causante del estímulo para la división celular. Ciertos VPH pueden en ocasiones romper los cromosomas de la célula huésped en puntos al azar, fragmentando así ciertos genes virales dentro del genoma del huésped (38). Este DNA del VPH integrado representa una mutación permanente, que se replicará con cada mitosis celular subsiguiente. En casi todos los casos el DNA viral integrado está interrumpido en la región temprana, en algún punto después de las ORF (Armazón Abierto de Lectura) E6 y E7, así que los genes relacionados con la ORF E6 y E7 deben jugar un papel importante en el proceso oncogénico
(20). Un contenido cromatínico aneuploide pronto se desarrolla en la célula huésped y le da una morfología displásica (17). La producción de DNA viral es mucho menor que en infecciones vegetativas y los producidos de gen tardío casi nunca aparecen. Por tanto, las células infectadas que presentan morfología displásica no suelen ser contagiosas. Ahora bien, la detención del ciclo vital del virus en las displasias de alto grado y cáncer, de manera que no se forman partículas virales (19) no significa para el virus una muerte biológica, ya que líneas celulares derivadas de carcinomas cervicales, como HeLa y Kaski, con la infección producen continuamente DNA viral de tipos específicos. Así que a pesar que el virus no se replica, el solo DNA puede ser infeccioso.

Los virus probablemente se tornan carcinogénicos en presencia de otros cofactores, como la radiación actínica, rayos $\mathrm{X}$, radiación Gamma, nicotina, estados de inmunodeficiencia (24) o interacción con otros virus como el Herpes II (3).

La morfología clínica del desorden en el crecimiento epitelial causado por el VPH depende en gran medida del grado de proliferación vascular: Si se presenta un crecimiento vascular extenso, las proyecciones del estroma serán visibles a simple vista como una papilomatosis. En contraste, si el crecimiento vascular es insufuciente para producir la verruga, las lesiones permanecerán subclínicas. Por lo demás, ambas manifestaciones, la exofítica o la expresión subclínica del VPH, representan infecciones virales vegetativas con efecto citopático viral prominente, y ambas pueden conducir a la interacción no productiva (por ejemplo, neoplásica) del virus con las células del huésped (34). La Infección Subclínica por VPH presenta morfología similar en la vulva, vagina, cérvix, ano, zona perianal, pene, mucosa oral, cuerdas vocales o en el esófago (12).

La respuesta inmune se inicia unos tres meses después de la aparición de las lesiones clínicas o subclínicas, dependiente de los linfocitos $\mathrm{T}$ (inmunidad celular). Existe también inmunidad dependiente de linfocitos B (anticuerpos) pero se considera que juega un papel menos importante que la dependiente de los linfocitos $\mathrm{T}$. en el 80 a $90 \%$ de los individuos, o los condilomas clínicos o subclínicos regresan expontáneamente o no continúan creciendo ni aparecen nuevas lesiones. Sin embargo, en el $10-20 \%$ de los individuos las lesiones activas siguen creciendo produciéndose un curso clínico refractario al tratamiento corriente (17).

Después de 9 meses de ocurrida la inoculación, los pacientes pueden ser divididos en dos grupos: Los que mantienen una a) remisión clínica sostenida y los que presentan nuevamente b) expresión activa de la enfermedad. Algunos de los primeros pueden permanecer contagiosos para nuevos compañeros sexuales, mientras que los del segundo grupo (expresión crónica activa o recaída después de cura aparente) son los de alto riesgo de progresión neoplásica (34).

Entre las cepas de VPH que infectan el tracto genital, los genotipos que se asocian a lesiones displásicas o cáncer son los denominados 16, 18, 31, 33 y 35 (25). El genotipo 18 se ha encontrado asociado a adenocarcinomas 
y carcinomas adenoescamosos del cérvix en proporciones significativas (26). Las lesiones displásicas, más avanzadas generalmente muestran la presencia de los genotipos 16-18-31 (29). Los genotipos 6 y 11 se encuentran en casi la totalidad de los condilomas acuminados y en algunas lesiones planas que generalmente desaparecen espontáneamente y que muy raramente dan origen a lesiones malignas (23).

Se han demostrado fluctuaciones geográficas en la prevalencia de los diferentes genotipos de VPH (33).

Estudios de laboratorio sustentan el papel de VPH como virus oncogénico: Los tipos 16-18 contienen regiones de su genoma que son capaces de transformar células in vitro (1). Adicionalmente, estudios apidemiológicos desarrollados en diversas partes del mundo han demostrado que la infección por VPH 16-18 está asociada con el cáncer cervical $(2,4-6)$.

La incidencia de cáncer cervical en América Latina es varias veces más alta que la observada en los países desarrollados, y en las ciudades latinoamericanas es la más alta del mundo (22), encontrándose una alta incidencia inexplicada de prevalencia de 16-18 en mujeres por lo demás sanas (7). Ya que el VPH 16-18 se encuentra asociado con la enfermedad maligna del cérvix, las mujeres que están infectadas con estos genotipos pueden tener un riesgo alto de desarrollar malignidad en relación con las mujeres infectadas con 6-11 que se ha encontrado asociado a lesiones benignas y NIC I (9).

El presente estudio busca establecer la prevalencia de los genotipos 6-11, 16-18 y 31-33-35 en biopsias cervicales de mujeres residentes en Bogotá.

\section{Material y Métodos}

\section{Especímenes examinados}

Del total de biopsias cervicales tomadas en el Servicio de Colposcopia del Hospital Militar Central de Bogotá, Colombia, entre agosto de 1989 y octubre de 1991 fueron seleccionadas, en cortes tenidos con hematoxilinaeosina, 266 con base en el criterio de infección por VPH (atipia coilocítica), presencia de Neoplasia intraepitelial o cáncer. Las biopsias cervicales, fijadas en formalina y embebidas en parafina, fueron remitidas al Laboratorio de Virología del Departamento de patología del Hospital Magee, Universidad de Pittsburgh, donde fueron revisadas por uno de los autores (AA) quien desconocía el diagnóstico original. En este informe se presentan los diagnósticos revisados.

\section{Hibridación In Situ (HIS)}

Se realizó siguiendo la misma metodología informada previamente por Amórtegui y Colaboradores (28).

\section{Resultados}

Del total de 266 biopsias examinadas, se encontró que $27(10.1 \%)$ tenían tejido insuficiente para una adecuada evaluación de la HIS, siendo 239 adecuadas. 12/239 casos correspondieron a cáncer invasor. La hibridación fue positiva en $81 / 239$ casos (33.9\%). El DNA del VPH $6-11$ se detectó en $6 / 81(7.4 \%)$ de los especímenes positivos, mientras que los tipos $16-18$ se encontró en $47 / 81$ (58.0\%), y los tipos 31-33-35 en 28/81 (34.6\%) (Tabla 1).

La correlación de los tipos de VPH con el diagnóstico histológico se muestra en la tabla 2 .

\section{Casos Sin Displasia}

Histológicamente, $115 / 239$ casos $(48.1 \%)$ correspondieron a la categoría de Sin Displasia, de los cuales 30 fueron informados como Normales, 67 con Atipia Inflamatoria, 2 con Atipia Reactiva, 14 con Cervicitis Crónica, 1 con Atrofia, y 1 Condiloma Plano.

\section{Tabla 1}

\section{PREVALENCIA SEGUN TIPOS DE VPH}

\begin{tabular}{|ll|}
\hline Tipos VPH & $\%$ casos positivos \\
\hline $6-11$ & $7.4 \%$ \\
\hline $16-18$ & $58.0 \%$ \\
\hline $31-33-35$ & $34.6 \%$ \\
\hline
\end{tabular}

Tabla 2

\section{DETECCION DE VPH EN BIOPSIAS CERVICALES MEDIANTE HIS}

\begin{tabular}{|lccrr|}
\hline Diagn Histológico & No. posit/total (\%) & \multicolumn{3}{c|}{ Tipos VPH en HIS posit(\%) } \\
& & $6-11$ & $16-18$ & $31-33-35$ \\
\hline Sin displasia & $26 / 115(21.73)$ & $4 / 26(15.3)$ & $13 / 26(50.0)$ & $9 / 26(34.6)$ \\
NIC I & $27 / 55(49.0)$ & $0 / 27(0.0)$ & $12 / 27(44.4)$ & $15 / 27(55.5)$ \\
NIC II & $14 / 37(37.8)$ & $1 / 14(7.1)$ & $12 / 14(85.5)$ & $1 / 14(7.1)$ \\
NIC III-CA in Situ & $11-20(55.0)$ & $1 / 11(9.0)$ & $7 / 11(63.6)$ & $3 / 11(27.2)$ \\
Cáncer infiltrante & $3 / 12(25.0)$ & $0 / 3(0.0)$ & $3 / 3(100)$. & $0 / 3(0.0)$ \\
\hline total & $81 / 239(33.89)$ & $6 / 81(7.4)$ & $47 / 81(58.0)$ & $28 / 81(34.6)$ \\
\hline
\end{tabular}


De los 30 casos Normales en 26 no se encontró evidencia histológica de infección por VPH, y en los 4 restantes fue dudoso el diagnóstico histológico de VPH. Uno de estos casos dudosos fue positivo en la HIS para 611 , y 1 caso sin evidencia histológica de infección por VPH fue positivo para 16-18.

De los 67 casos con Atipia Inflamatoria, 38 presentaron evidencia histológica de infección por VPH, 11 dudosos y 18 negativos. Ninguno de estos casos histológicamente negativos para VPH fue positivo en la HIS. En los casos dudosos se presentó 1 caso positivo a la HIS para 6-11 y otro para 31-33-35. En los casos positivos histológicamente al VPH hubo 2 casos positivos para los grupos 6-11, 11 casos positivos para los grupos 16-18 y 7 casos positivos para los grupos 31-33-35.

Los 2 casos con diagnóstico de Atipia Reactiva fueron positivos histológicamente para VPH, uno de los cuales fue positivo para 16-18.

De los 14 casos informados como Cervicitis Crónica, 9 fueron negativos histológicamente para VPH, 3 positivos a la histología y 2 dudosos. 1 de los casos positivos a la histología fue positivo a la HIS para 31-33-35.

El caso de Atrofia fue positivo histológicamente para VPH. Ni en el caso de Atrofia ni en el caso de Condiloma Plano se demostró a la HIS VPH.

\section{Casos Neoplasia Intraepitelial Cervical}

Las prevalencias del DNA VPH demostradas para el NIC I, II, III-CA in situ fue de 16-55 (49.09\%), 14/37 $(37.83 \%)$ y $11 / 20(55 \%)$ respectivamente.

\section{Casos Cáncer Infiltrante}

De los 12 casos de cáncer invasor, 6 presentaron evidencia histológica de infección por VPH, en 2 fue dudosa dicha infección, y negativa en 4.3 de los 12 casos fueron positivos a la HIS para 16-18. No se presentó positividad para otros genotipos. Para el cáncer infiltrante la prevalencia del DNA VPH fue de $3 / 12$ (25\%).

La asociación de los genotipos de VPH con el Grado de la Lesión en esta muestra de Bogotá, se muestra en la tabla 3 .

Tabla 3

ASOCIACION DE LOS TIPOS DE VPH CON EL GRADO DE LA LESION, BOGOTA

Bajo Grado: ISP y/o NIC I

Alto Grado: NIC II, NIC III, CA in situ.

\begin{tabular}{|lccc|}
\hline Lesión & $\begin{array}{c}\text { tipos } \\
6-11\end{array}$ & $\begin{array}{c}\mathrm{v} \mathrm{p} \mathrm{h} \\
16-18-31-3-5\end{array}$ & total \\
\hline Bajo Grado & 4 & 49 & 53 \\
Alto Grado & 2 & 23 & 25 \\
Total & 6 & 72 & 78 \\
\hline
\end{tabular}

Chi2 $=0.15, \mathrm{p}<0.7 \mathrm{NS}$
El diagnóstico histológico de VPH se realizó en 149/ $239(62.39 \%$ ) de los casos, fue dudoso en $26 / 239$ (10.87\%) y negativo en 64/239 (26.77\%).

\section{Discusión}

No todos los métodos empleados para la demostración del VPH son igualmente sensibles. En la actualidad, la microscopía del corte histológico es todavía el método más frecuente y conveniente de diagnóstico de infección por VPH (12), siendo altamente específico aunque no muy sensible. Parece ser que sólo 10 del $30 \%$ de las infecciones por VPH pueden diagnosticarse en corte histológico (12). El diagnóstico histológico se basa en el efecto citopático del virus sobre el epitelio. Aunque se ha sugerido que las lesiones de Bajo Grado que contienen atipos de VPH oncogénicos pudieran identificarse por la presencia de mitosis atípicas (30), varias investigaciones posteriores no han podido predecir los tipos de VPH con base en las solas características histopatológicas $(16,31$, 32). Las infecciones vegetantes son distintivas de los VPH de bajo riesgo oncogénico. Sin embargo, al menos $10-15 \%$ de las lesiones cervicales histológicamente benignas contienen tipos de VPH de alto riesgo (16).

La demostración del VPH mediante frote citológico es altamente específica pero muy poco sensible: Los hallazgos citológicos dell VPH muestran en la población general una prevalencia de tan sólo 1-2\% (8).

La sensibilidad del método de Hibridación depende de la cantidad de moléculas de ácido nucleico de VPH que sea capaz de detectar. Si solo una célula en un millón contiene 10.000 moléculas virales $(0.01$ moléculas por célula), la hibridación in situ (como la aplicada en este estudio) detectará una célula positiva, en tanto que la hibridación de mancha Southern y puntiforme serán negativas. Por otro lado, si solo un millón de células contienen cada una molécula viral, las pruebas de mancha Southern y puntiforme serán positivas en tanto que la hibridación in situ es negativa. Si hay menos de 1.000 copias del genoma viral en una muestra distribuida en más de 100 células, puede detectarse la presencia de VPH solo por amplificación de DNA (PRC) (21).

En estudios previos hechos en mujeres de EEUU y aplicando la misma metodología en biopsias que no incluyeron cáncer infiltrante (28), se han descrito valores semejantes de positividad a la HIS del VPH (40\% vs $34.4 \%$ del presente estudio, $\mathrm{Zi}=1.51, \mathrm{p}(\mathrm{Zi})<0.06 \mathrm{NS})$, existiendo una diferencia significativa en la prevalencia de los diferentes tipos, especialmente para VPH 6-11, lo que confirma una variación geográfica de la prevalencia de los diferentes tipos (Tabla 4).

El sistema de diagnóstico tradicional basado en la diferenciación entre displasia y carcinoma in situ, no ha sido útil para identificar lesiones particulares que sufren transformación maligna. Algunas displasias evolucionan hacia el cáncer, pero paradójicamente casi ninguno de los carcinomas in situ (33). En aquellas pacientes con cáncer cervical, el progreso maligno puede requerir desde 12-18 meses hasta 20 años y puede presentarse en pacientes que inicialmente tenían solo Displạsia Leve (18). La atipia 
Tabla 4

PREVALENCIA DE LOS TIPOS DE VPH, COMPARACION ENTRE BOGOTA Y PITTSBURGH. NO SE INCLUYEN CASOS DE CANCER INVASOR

\begin{tabular}{|lrrrc|}
\hline VPH & Bogotá & Pittsburgh & Zi & $p(Z i)$ \\
\hline $6-11$ & $6 / 78$ & $101 / 314$ & 4.34 & $<0.001$ \\
$16-18$ & $44 / 78$ & $137 / 314$ & 2.03 & $<0.02$ \\
$31-33-35$ & $28 / 78$ & $76 / 314$ & 2.09 & $<0.02$ \\
\hline
\end{tabular}

cervical leve en un $26 \%$ de los casos evoluciona a NIC III en un período de dos años, mientras que la tasa de represión se ha descrito tan sólo de $11 \%$. Se ha informado que el $85 \%$ de las displasias que progresan a lesiones de alto grado son positivas para VPH 16 (15). La tipificación del VPH (y también el análisis de suploides o aneuploidea) puede subdividir las lesiones relacionadas con VPH no invasivas, en grupos con evolución biológica muy diversa. A pesar de una superposición notoria entre las lesiones de Alto Grado (NIC II-III) y bajo Grado (NIC I e infecciones subclínicas del VPH), la identificación del tipo de VPH puede distinguir lesiones precursoras de enfermedad maligna de aquellas con proliferación benigna (17). Estudios de vigilancia indican que las displasias positivas para VPH 16 tienen más posibilidades de evolucionar hacia un grado elevado de anormalidad, que las que contienen VPH 6 u 11 (11).

En Bogotá la prevalencia combinada de los genotipos 16-18 y 31-33-35 es igual tanto para las lesiones de BajoGrado como para las de Alto Grado, mientras que en Pittsburgh (representativo de lo informado en la literatura internacional) existe asociación significativa de estos genotipos con la mayor severidad de las lesiones (Tabla 5).

\section{Conclusiones}

Los hallazgos que en esta muestra de Bogotá hay una baja prevalencia de VPH tipos 6-11 y alta prevalencia

\section{Tabla 5 \\ PREVALENCIA COMBINADA DE LOS \\ GENOTIPOS 16-18 Y 31-33-35 PARA LAS \\ LESIONES DE BAJO GRADO Y ALTO GRADO. COMPARACION ENTRE BOGOTA Y PITTSBURGH}

Bajo Grado: HIS positivo y/o NIC I

Alto Grado: NIC II, NIC III, CA in Situ.

\begin{tabular}{|lll|}
\hline & Bogotá & Pittsburgh \\
\hline Bajo Grado & $49 / 53(92.4 \%)$ & $166 / 261(63.6 \%)$ \\
Alto Grado & $23 / 25(92.0 \%)$ & $47 / 53(88.7 \%)$ \\
Bogotá: & $\mathrm{Zi}=0.07, \mathrm{p}(\mathrm{Zi})<0.5 \mathrm{NS}$ \\
Pittsburgh: & $\mathrm{Zi}=3.56, \mathrm{p}(\mathrm{Zi})<0.001$ \\
\hline
\end{tabular}

combinada de los tipos 16-18 y 31-33-35, y que las displasias tanto de bajo como de alto grado tienen una elevada prevalencia de los tipos de alto riesgo oncogénico, son consistentes con los estudios epidemiológicos que demuestran que en esta zona geográfica se encuentran los índices más altos del mundo de Carcinoma de Cérvix.

\section{BIBLIOGRAFIA}

1. Villa L., Bretani R. Human papillomavirus Up-Date. Int. J. Cancer 1991; 48: 163.

2. Reeves W., Brinton L., Garcia M., Brenes M., Herrero R., Gaitan E., Tenorio E., de Britton R., Rawls W. Human Papillomavirus infection and cervical cancer in Latin America. New. Engl. J. Med. 1989; 320: 1437.

3. Hildesheim A., Mann V., Briton LA., Szklo M., Reeves WC., Rawls WE. Herpes simplex virus type 2: A posible interaction with Heuman Papillomavirus Types $16 / 18$ in the development of invasive cervical cancer. Int. J. Cancer 1991; 49: 335-340.

4. Brenes M., Loo S., Gomez B., Reeves W. Estudio controlado de casos de Cáncer Cervicouterino e Infección con el Virus papiloma Humano en América Latina. Rev. Med. Panama 1987; 12: 173.

5. Villa L., Franco E. Epidemiologic Correlates of Cervical Neoplasia and Risk of Human Papillomavirus Infection in Asymptomatic Women in Brazil. J. National Cancer Inst. 1989; 81: 332.
6. Herrero R., Brinton L., Reeves W., Brenes M., Tenorio F., de Britton R., Gaitan E., Montalvan P., Garcia M., Rawls W. Risk Factors for Invasive Carcinoma of the Uterine Cervix in Latin America. Bull PAHO 1990; 24: 263.

7. Reeves W., Caussy D., Brinton L., Brenes M., Montalvan P., Gomez B., de Britton R., Morice E., Gaitan E., Loo S., Rawls W. Case-control Study of Human Papillomaviruses and Cervical Cancer in Latin America. Int. J. Cancer 1987; 40: 450.

8. Waeckerlin R., Potter N., Cheatham R. Correlation of cytologic, colposcopic, and histologic studies with immunohistochemical studies of human papillomavirus structural antigens in an unselected patient population. Am. J. Obstet. Gynecol. 1988; 158: 1394.

9. McCance DJ., Campion MJ., Clarkson PK., Chesters PM., Jenkins D., Singer A. Prevalence of human papillomavirus type 16 DNA sequences in cervical intraepithelial neoplasia and invasive carcinoma of cervix. British J. Obstet. Gynecol. 1985; 92: 1101-1105. 
10. Syrjanen K., Vayrynen M., Saarikoski S., Mantyjarvi R., Parkkinen S., Hippelainen M., Castren O. Natural history of cervical human papillomavirus (HVP) infections based on prospective follow-up. British J. Obstet. Gynecol. 1985; 92: 1086-1092.

11. Campion MJ., Cuzick J., McCance DJ., Singer A. Progressive potential of mild cervical atypia: Prospective cytological, colposcopic, and virological study. Lancet 1986; 2: 237.

12. Schneider $V$. Diagnóstico microscópico de infección por papilomavirus humano. Clin. Obstet. Ginecol. 1989; 1: 143-150.

13. Reid R. Lesiones del cuello uterino relacionadas con papilomavirus humano: Biología y características colposcópicas. Clin. Obstet. Gin. 1989;1: 151-171.

14. Reid R. Biology and Colposcopic feactures of Human papillomavirus - associated Cervical Disease. Obstet and Gynecol. Clin North America 1993; 20: 123 .

15. Campion M., McCance D., Cuzick J., Singer A. progressive potential of mild cervical atypia: Prospective cytological and virological study. Lancet 1986; ii: 237.

16. Reid R., Greenberg M., Jenson A., Husain M., Willett J., Daoud Y., Temple G., Stanhope C., Sherman A., Phibbs G., Lorincz A. Sexually transmitted papillomaviral infections. I. The anatomic distribution and pathologic grade of neoplastic lesions associated with different viral types. Am. J. Obstet. Gynecol. 1987; 156: 212.

17. Reid R. Human papillomaviral infection. The key to rational triage of cervical neoplasia. Obstet. Gynecol. Clin. North Am. 1987; 14: 407.

18. Koss L., Stewart F., Foote F et al. Some histological aspects of behavior of epidermoid carcinoma in situ and related lesions of the uterine cervix. Cancer 1963; 16: 1160.

19. Smotkin D. Virología del papilomavirus humano. Clin. Obstet. Ginecol. 1989; 1: 117.

20. Schwarz E., Freese U., Gissman L et al. Structure and transcription of human papillomavirus sequences in cervical carcinoma cells. Nature $1985 ; 314: 111$.

21. Schneider A., Grubert T. Diagnóstico de infección por papilomavirus humano con tecnología de DNA recombinante. Clin. Obstet. Ginecol. 1989; 1: 125.

22. Restrepo HE., Gonzalez J., Roberts Eet al. Epidemología y control del cáncer del cuello uterino en América Latina y El Caribe. Bol Of Sanit Panam 1987; 102: 578-593.

23. Wright TC, Richard RM. Role of human papillomavirus in the pathogenesis of genital tract warts and cancer. Gynecol Oncol 1990; 37: 151-164.

24. Amortegui AJ., Meyer MP., Kunschner L., Saker A. Demostration of Human papillomavirus DNA by Nucleic Acid In Situ Hybridization in Paired Histologically Abnormal Cervical Biopsies obteined at the same patient visit. J. Clin. Lab. Anal. 1991; 5: 268-274.
25. Reid R., Campion MJ. The biology and significance of human papillomavirus in the genital tract. Yale J. Biol. Med. 1988; 61: 307325.

26. Tase T., Okagaki T., Clak BA., Twiggs LB., Ostrow RS., Faras AJ. Human papillomavirus DNA in adenocarcinoma in situ, microinvasive adenocarcinoma of the uterine cervix, and coexisting cervical squamous intraepitelial neoplasia. Int. J. Gynecol. Pathol. 1989; 8: 8. 17.

27. Amortegui AJ., Meyer MP. In Situ Hybridization for the Diagnosis and Typing of Human Papillomavirus. Clin Biochem 1990; 23: 301306.

28. Meyer MP., Markiw CA., Matuscak RR., Saker A., McIntyre-Seltman K., Amortegui AJ. Detection of Human Papillomavirus DNA in Genital Lesions by Using a Modified Commercially Available In Situ Hybridization Assay. J. Clin. Microbiol. 1991; 29: 1308-1311.

29. Amortegui AJ., Meyer MP., McIntyre-Selman K., Locker J. Detection of Human Papillomavirus DNA in Cervical Lesions in Situ Hybridization Using Biotinylated DNA Probes. International J. Gynecol. Pathol. 1990; 9: 306-315.

30. Crum CP., Ikenberg H., Richart RM., Gissmann L. Human Papillomavirus type 16 and early cervical neoplasia. N. Engl. J. Med. 1984; 310: 880 .

31. Jenkins D., Tay SK., McCance DJ et al. Histological and immunocy tochemical study of cervical intraepithelial neoplasia (CIN) with associated HPV 6 and HPV 16 infections. J. Clin. Pathol. 1986; 39: 1177.

32. Kadish AS., Burk RD., Kress Y., Calderin S. Romney SL. Human papillomaviruses of different types in precancerous lesions of the uterine cervix: Histologic, immunocytochemical and ultrastructural studies. Hum. Pathol. 1986; 17: 384.

33. Pfister H. Relationship of Papillomaviruses to Anogenital Cancer. Obst. Gynecol. Clin. N. Amer. 1987; 14: 349-361.

34. Stone KM. Aspectos epidemiológicos de la infección genital por papilomavirus humano. Clin. Obstet. Ginecol. 1989; 1: 111.

35. Koutsky LA., Galloway DA., Holmes KK. The epidemiology of genital papillomavirus infection. Epidemiol. Rev. 1988; 10: 122.

36. Lorincz A., Temple G., Patterson JA. Correlation of cellular atypia and HVP DNA sequences in exfoliated cells of the uterine cervix. Obstet. Gynecol. 1986; 68: 508.

37. Stoler MH., Broker TR. In Situ hybridization detection of human papillomavirus DNA and messenger RNA in genital condylomas and in cervical carcinoma. Hum. Pathol. 1986; 17: 1250.

38. Schwarz EH., Freese UK., Gissman L. Structure and transcription of HVP sequences in cervical cancer cells. Nature 1985; 314: 111. 